\title{
Protein/Amino Acid Biochemistry, Synthesis
}

National Cancer Institute

\section{Source}

National Cancer Institute. Protein/Amino Acid Biochemistry, Synthesis. NCI Thesaurus.

Code C18974.

Protein synthesis occurs in the cell by translating the sequential codons in messenger RNAs into amino acid residues of a peptide chain. This translation physically occurs in macromolecular complexes called ribosomes, pairing amino acid-carrying transfer RNA complexes with individual codons of the messenger RNA, transferring the elong ating peptide to this tRNA-amino acid complex with formation of a peptide bond, releasing the previous tRNA, and translocating the messenger RNA to make the next codon available for pairing. The process is then repeated until a termination codon is read and the peptide is released. 